\title{
Morphological characterization of forage sorghum genotypes for its various DUS traits
}

\author{
Nabin Bhusal ${ }^{1}$, S.K. Pahuja ${ }^{1 *}$, Akshay Kumar Vats ${ }^{1}$, Ashutosh Srivastava ${ }^{2}$ and Ravi \\ Shekhar Kumar ${ }^{2}$ \\ ${ }^{1}$ Department of Genetics and Plant Breeding, CCS Haryana Agricultural University Hisar-125004(Haryana), \\ INDIA \\ ${ }^{2}$ ICAR- Indian Institute of Wheat and Barley Research, Karnal-132001 (Haryana), INDIA \\ *Corresponding author. E-mail: pahujask66@gmail.com
}

Received: July 9, 2016; Revised received: February 10, 2017; Accepted: April 30, 2017

\begin{abstract}
The present investigation was conducted to characterize 20 genotypes of sorghum \{Sorghum bicolor (L.) moench\} on the basis of 33 morphological characters provided by Protection of Plant Variety \& Farmer's Right Act (PPV\&FRA) for Distinctiveness Uniformity and Stability (DUS) testing in sorghum. Experimental results revealed that maximum variation was found on the basis of glume colour among the genotypes i.e. G 46, HC 308, HJ 513 had green white, IS 3237, SSG 9, HC 171 had yellow white, SSG 59-3, COFS 29 had grayed purple, S 437-1, SGL-87, S 540-S, SSG (PSSG) had grayed yellow and remaining seven genotypes had grayed orange glume colour. The studied traits showed five genotypes had distinct state of expression. Genotype S-540 showed very high plant height upto the base of flag leaf, $\mathrm{HC} 136$ had compact panicle density at maturity, COFS 29 had very long glume length, SSG 59-3 had distinct expression for days to panicle emergence (50\% of the plants with $50 \%$ of anthesis) and COFS 29 and IS 18551 had short and very long leaf width of blade, respectively. The Principal Component Analysis (PCA) revealed principal Factor (PFI) and Principal Factor (PFII) with maximum variability (64.99 \%). Classification of genotypes on the basis of DUS traits provided identification of key characteristics of various genotypes.
\end{abstract}

Keywords: DUS, Forage, PPV and FRA, Principal component analysis, Sorghum bicolor

\section{INTRODUCTION}

Sorghum is one of the five top cereal crops in the world. It is extremely drought tolerant, making it an excellent choice of forage, grain and ethanol production for arid and dry areas (Ali et al. 2009). Due to quick growing habit, high yield regeneration potential, better palatability, digestibility and drought tolerance makes it good choice of fodder for farming community on which the livestock industry depends. It can grow in the areas, where all other major cereal crops could not grow successfully. Fodder production is an important traditional part of the present cropping system. Lack of quality fodder, is one of the major constraints to improve livestock production. Cattle are fed both on rangelands and in the sheds, however, many animals are underfed and weak due to lack of quality feed. Forage crops like sorghum play major role for the fulfillment of quality fodder demand without decreasing the amount of production for livestock industry. Development of broad genetic base, high yielding and stable sorghum cultivars are required to overcome these problems.

India has enormous diversity of sorghum in both cultivated and wild species. There is a need of consolidated system in the country to protect such a vast variability present in the species and proper sharing of benefits derived by utilization of these species. Descriptors of varieties of crop species are required for characterization of varietal identity, determination of varietal purity, establishment of the distinctiveness of new variety from existing varieties and documentation of genetic resources (Anonymous, 2007).

To encourage public and private investment in research and development of new varieties, government of India enacted "The Protection of Plant Varieties and Farmers' Right Act (PPV\&FR Act)" in 2001, by providing protection to the plant varieties against unauthorized multiplication of seeds or propagating materials for specific period. Registration and protection can be granted to a variety only if it conforms to the criteria of Distinctness, Uniformity and Stability. It means that the new variety has to be Distinct-UniformStable (DUS) in its characteristics (Anonymous, 2001; Anonymous, 2004). Such characteristics may be morphological, biochemical, molecular or any other nature. Characterization of varieties is thus of significance for the purpose of establishment and verification of identity and assessment of varietal purity for seed production and certification (Singh et al., 2016). Previously study on diversity of inter specific sorghum has 
been reported using agro-morphological traits by various researchers (Ayana and Bekele, 2000; Joshi et al. 2009; Reddy et al., 2009; Kannababu et al., 2013; Raghuvanshi et al., 2014). It is therefore, important to identify key diagnostic traits of different genotypes. This allows breeder to select genotypes with distinct characters in crop improvement programme. Keeping above in consideration present investigation was undertaken to characterize 20 forage sorghum genotypes for DUS traits.

\section{MATERIALS AND METHODS}

Plant materials: The experimental material consisted of 20 forage sorghum genotypes comprising six released $\&$ notified varieties and 14 were indigenous selections from the different parts of the country along with their pedigree (Table 1).
Experimental site and data collection: The experiment was conducted during kharif season of 2011 in Research Area, Forage Section, Department of Genetics and Plant breeding, CCS Haryana Agricultural University, Hisar. The experiment was planted, as per DUS guidelines, in a randomized block design with four replications. Each line was accommodated in a plot of 6 rows of $6 \mathrm{~m}$ length spaced at $60 \mathrm{~cm}$ row to row and $15 \mathrm{~cm}$ plant to plant.

Data were recorded on 33 morphological characters at seedling, panicle emergence, flowering, physiological maturity, after maturity and seed characteristics which were maintained in the guideline for DUS testing in sorghum. The colour chart of Royal Horticultural society was used to record the visual characters. Observations were recorded in selected five plants of each genotype in each replication.

Table 1. Selected genotypes in the experiment along with their pedigree and source.

\begin{tabular}{llll}
\hline S. N. & Genotypes/lines & Pedigree & Source \\
\hline 1 & S-437-1 & S 153/V 60-1 X Sorghum roxburghii/P-1-3-7-1-1 & CCS HAU, Hisar \\
2 & IS 3237 & Purdue 81247 & Purdue, USA \\
3 & G 46 & Selection from S 202 which is a selection from cross 10626B X 6090 M3-1-1 & CCS HAU, Hisar \\
4 & IS 18551 & Jijwejere 935 (Landrace) & Ethiopia \\
5 & SGL 87 & Selection from IS 3274 & Ludhiana \\
6 & HC 308 & SPV 8X IS 4776 (Durra) & CCS HAU, Hisar \\
7 & SS 59-3 & Non sweet Sudan grass X JS 263 & CCS HAU, Hisar \\
8 & COFS 29 & TNS 30X Sorghum sudanense) & Coimbatore \\
9 & HC 136 & IS 3214 (bicolor) X PC7R & CCS HAU, Hisar \\
10 & S 540 & Selection from S 512 which is further a selection from P 33 & CCS HAU, Hisar \\
11 & HJ 513 & Selection from a cross (S305XPJ7RXSPV80)X HC 136 & CCS HAU, Hisar \\
12 & IS 2389 & Mimosa Park Q 2-5-73 & South Africa \\
13 & SSG (PSSG) & Selection from M6 generation of SSG 59-3 & CCS HAU, Hisar \\
14 & IS 2205 & Jaglur a selection from Karnatka & DSR, Hyderabad \\
15 & S 490-1 & Selection in F6 generation from a cross S 178 X SPV 394 & CCS HAU, Hisar \\
16 & IS 651-5 & Selection from IS 651 & DSR, Hyderabad \\
17 & SSG 9 & Selection from M6 generation of SSG 59-3 & CCS HAU, Hisar \\
18 & SSG 5 (22) & Selection from M6 generation of SSG 59-3 & CCS HAU, Hisar \\
19 & HJ 541 & Selection from S241 which is selection from a cross SPV 80X29/1 P20-1-1-2 & CCS HAU, Hisar \\
20 & HC 171 & SPV 8 X IS 4776 (Durra) & CCS HAU, Hisar \\
\hline
\end{tabular}

Table 2. Factor loading of different characters with respect to different principal factors.

\begin{tabular}{|c|c|c|c|}
\hline Characters & F1 & F2 & F3 \\
\hline Length of flag leaf $(\mathrm{cm})$ & $0.577^{*}$ & $0.500^{*}$ & $0.526^{*}$ \\
\hline Width of flag leaf $(\mathrm{cm})$ & -0.461 & $0.773 *$ & 0.127 \\
\hline Stem diameter $(\mathrm{cm})$ & $-0.860 *$ & 0.202 & -0.183 \\
\hline Anther length (mm) & -0.062 & $0.571 *$ & -0.360 \\
\hline Stigma length & $-0.531 *$ & 0.430 & -0.239 \\
\hline Plant height & $-0.676^{*}$ & -0.378 & $0.564 *$ \\
\hline Leaf length & $0.705 *$ & 0.261 & 0.352 \\
\hline Leaf width & $-0.780 *$ & $0.518 *$ & -0.111 \\
\hline Neck of panicle above the sheath & $0.762 *$ & -0.442 & -0.003 \\
\hline Panicle length without peduncle & $0.912 *$ & -0.032 & 0.154 \\
\hline Panicle length of branches & $0.920^{*}$ & -0.060 & 0.115 \\
\hline Dry fodder yield/plant(g) & $-0.773 *$ & -0.378 & 0.458 \\
\hline Green fodder yield/plant (g) & $-0.691 *$ & -0.335 & $0.559 *$ \\
\hline TSS content $(\%)$ & 0.399 & $0.539 *$ & 0.404 \\
\hline 1000 grain weight $(\mathrm{g})$ & $-0.820 *$ & -0.034 & 0.318 \\
\hline $50 \%$ flowering & -0.186 & $-0.662 *$ & -0.494 \\
\hline Eigen values & 7.33 & 3.065 & 2.034 \\
\hline Variability per cent & 45.83 & 19.15 & 12.71 \\
\hline Cumulative per cent & 45.83 & 64.98 & 77.69 \\
\hline
\end{tabular}




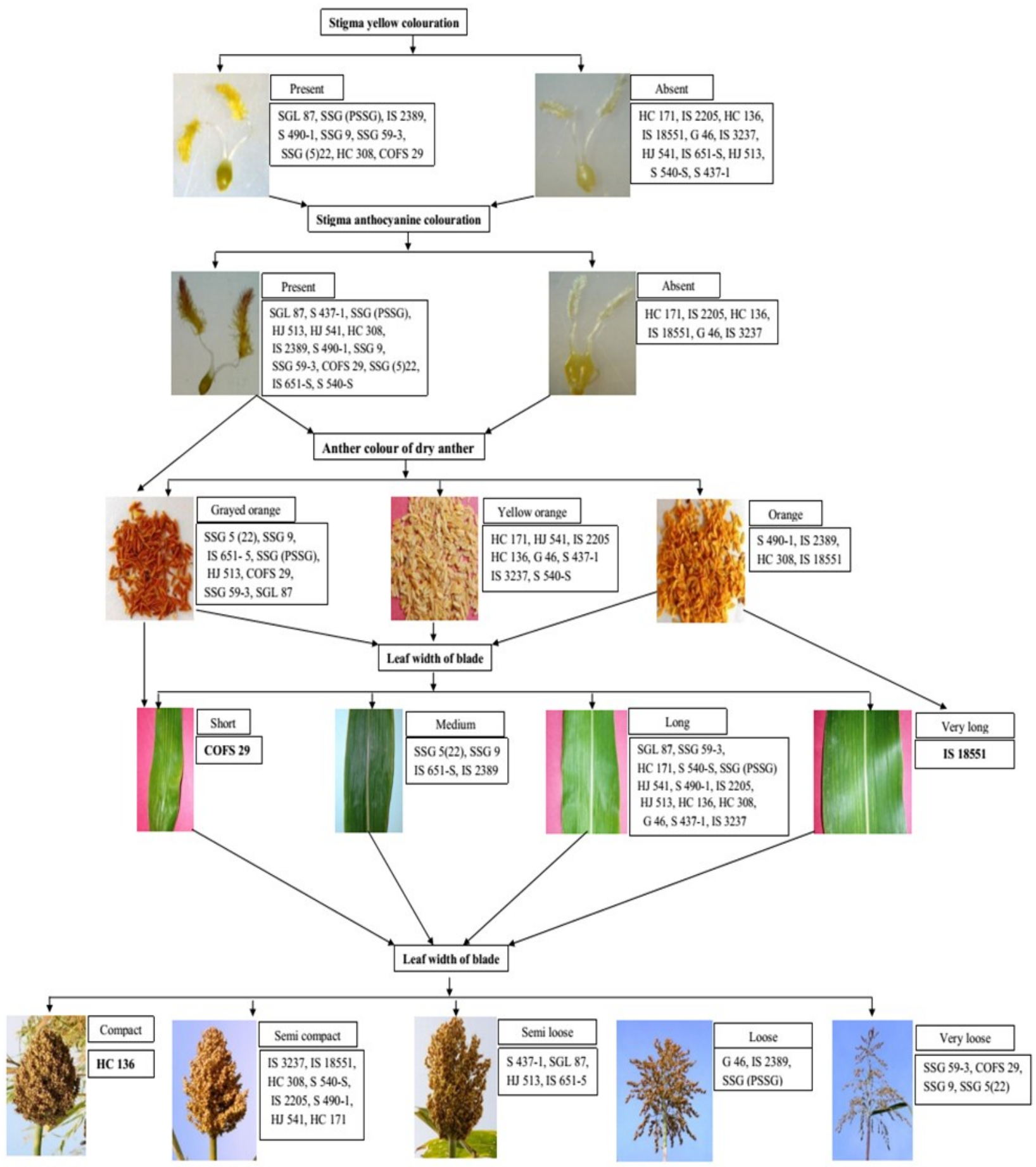

Fig. 1. Kew diagnostic characters of sorghum on the basis of qualitative characters.

Data interpretations and analysis

Qualitative traits: Genotypes were classified in different groups on the basis of various states of the characters provided in the guidelines of PPV and FRA authority for DUS testing in sorghum. Before considering the genotypes in particular state of the character, recorded data were analyzed individually and states of expression of the character were observed in each replication. After that maximum expression state is considered as the genotypes expression for that character. Whereas, differences between two genotypes were considered clear if the expression of one or more characteristics fell into two different states in the test guidelines.

Quantitative traits: To differentiate genotypes in various states of the quantitative characters average performances of the genotypes in all the replications were considered as a final expression of the genotypes. 


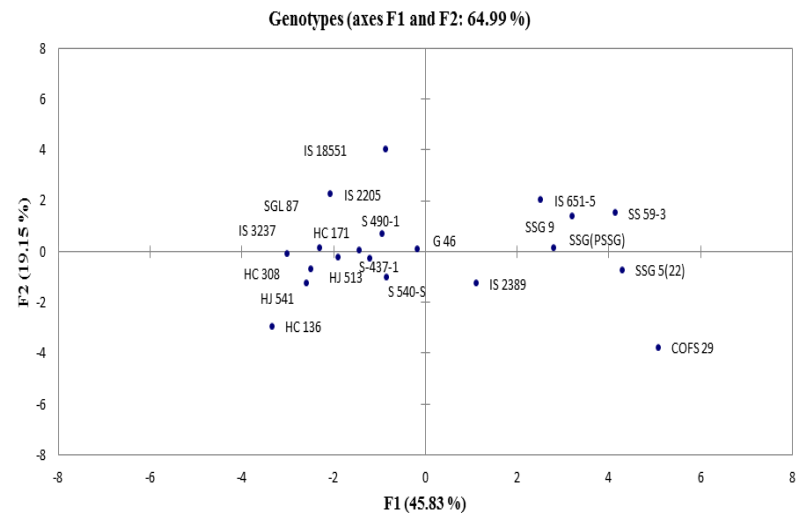

Fig 2. Positions of the genotypes based on the variation showed by factor I and factor II.

Average performances of selected 16 characters were used for principal component analysis. Principal component analysis was done using software XLSTAT 2014.

\section{RESULTS AND DISCUSSION}

Genetic variability is key component for any breeding programme, whereas characterization provides basis for selection to better genotypes from the variable population. The detailed examination of diagnostic characteristics is an important task to maintain identity of released and notified varieties and their parental lines. Thus, accurate description and identification of sorghum varieties are crucial for DUS testing. Varieties are registered with National Bureau of Plant Genetic Resources (NBPGR) based on the characteristics which are useful to establish distinctiveness, uniformity and stability of variety prescribed in the DUS test guidelines of sorghum. Twenty genotypes were characterized based on DUS guidelines provided by PPV and FRA. All genotypes were classified into different groups based on various traits associated with seedling, flowering, physiological maturity and seed characteristics. When all the 33 morphological characters (Table 3) were considered, distinct characters could also be obtained for five genotypes S-540, SSG 59-3, COFS 29, HC 136 and IS 18551 for the characters plant height up to the base of flag leaf, days to panicle emergence, width of blade, panicle density at maturity and width of blade, respectively. Genotype S-540 showed very tall height of plant up to the base of flag leaf, SSG 59-3 genotype showed medium days to panicle emergence $(50 \%$ of the plant with $50 \%$ of anthesis), genotype COFS 29 showed short leaf width of blade and very long glume length, HC 136 genotype showed compact panicle density at maturity and genotype IS 18551 showed very long width of blade (Fig. 1). Rakshit et al. (2012) studied the variability among sorghum maldandi landraces and found Thirteen promising Maldandi accessions selected based on field performance as well as morphological and molecular diversity.

In two characters, seedling anthocyanine colouration of coleoptiles and leaf sheath anthocyanine colourtaion, all genotypes showed similar (i.e. yellow green and grayed purple) expression. Some of the genotypes particularly SSG series exhibited grayed purple seedling and also found pigmentation in their seed colour. This may indicate that pigmentation in seedling and leaf may be associated with tannin content in seeds. Earp et al., 2004 reported that purple pigmentation on the leaves is closely associated with the seed colour and tannin content of the grains. Whereas, Elangovan et al. (2007) found dark green leaves for most of the 400 accessions of sorghum in his study. The possible reason for this could be differences of genetic material in both the studies for this trait. On the basis of leaf midrib colour, the genotypes were categorized into two groups: white (8 genotypes) and yellow green (12 genotypes). Sangwan et al. (2005) and Elangovan et al. (2007) characterized 12 and 157 sorghum genotypes on the basis of midrib colour (white and green), respectively. Reddy et al. (2008) studied inheritance of midrib colour (brown and white) in 8 segregating populations of sorghum. Durrishahwar et al. (2012) reported ample variation for midrib colours in sorghum viz., white, light yellow, yellow, light green and dark green. Days to $50 \%$ flowering and plant height at the time of flowering is critical for fodder production. It is directly associated with the environmental conditions and fluctuations in the durations which adversely affect Crop maturity, fodder production, fodder quality, harvesting and grain quality. In present experiment most of the genotypes were late to very late flowering and tall in height (Table 3). Tall plants of sorghum can easily lodge but are beneficial for fodder, biomass fuel and thatching. Madhusudhana and Patil, (2013) reported wide variations of plant height in sorghum. Elangovan (2006) characterized 179 accessions of sorghum on the basis of days to $50 \%$ flowering along with other morphological characters. Reddy et al. (2009) studied divergence and genetic variability of 29 sorghum genotypes on the basis of time of panicle emergence. Nabi et al. (2006) compared 5 advance lines of sorghum on the basis of stem thickness, plant height and leaf area.

On the basis of stigma anthocyanine colouration and stigma yellow colouration genotypes were divided into two groups each (Fig. 1). Among them six genotypes were having stigma anthocyanine colouration, while fourteen other genotypes were not having anthocyanine colouration. In case of stigma yellow colouration, eleven genotypes were having yellow colouration in their stigma among twenty genotypes. Moreover, eight genotypes were yellow orange, four genotypes were orange and eight genotypes were grayed orange in their colouration of dry anther (Fig. 1). However, only the character panicle density at maturity was able to provide distinct states of expression for single genotype 
Nabin Bhusal et al. / J. Appl. \& Nat. Sci. 9 (2): 912 - 919 (2017)

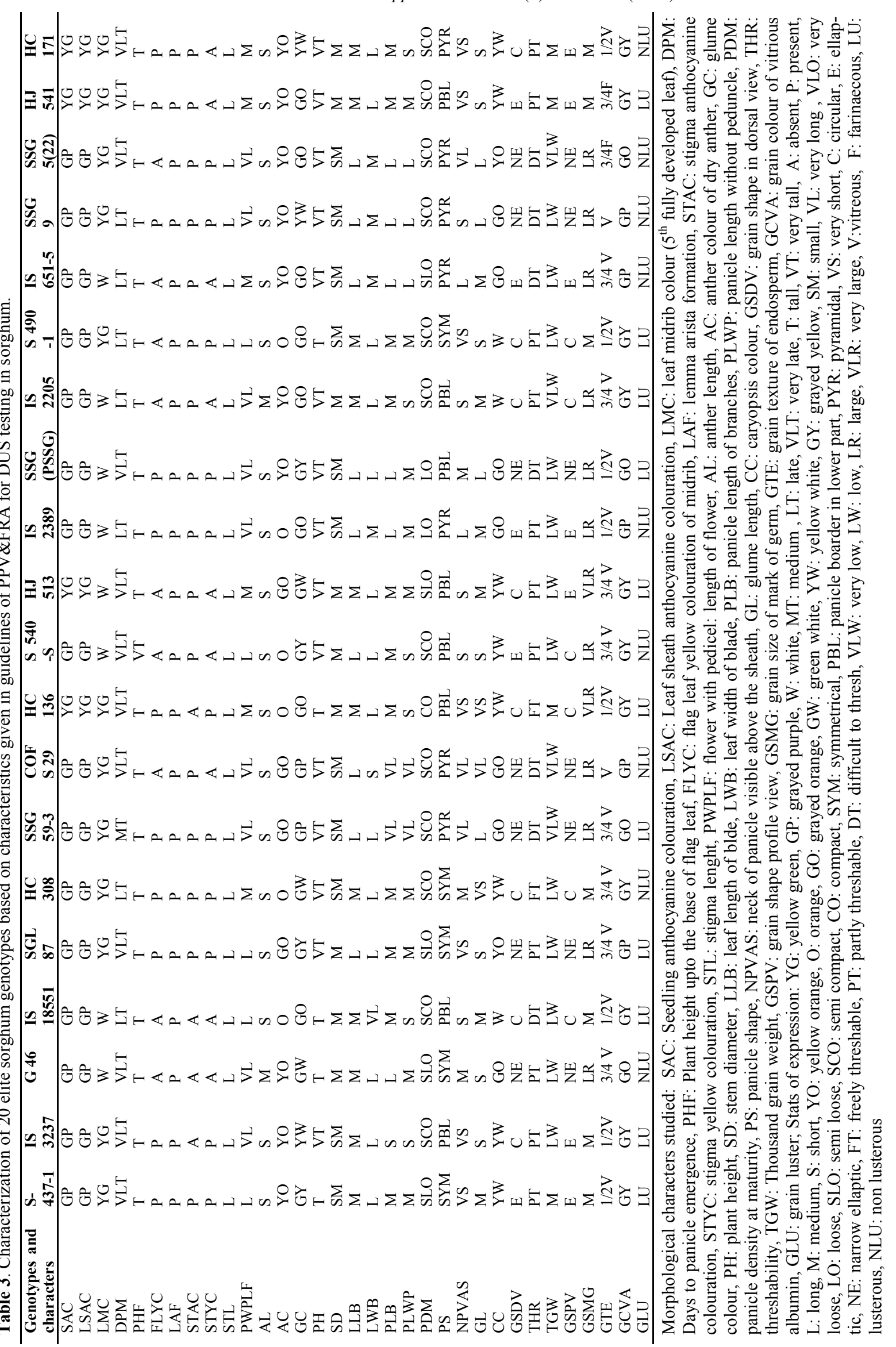


HC 136.

Characters like panicle shape, compactness, glume colour, glume length and panice length may directly associate with grain yield in sorghum. Variation in these characters provided basis for selection to best character associated with high yield. Based on panicle density at maturity genotypes could be divided into five categories viz., very loose (four genotypes), loose (three genotypes), semi loose (four genotypes), semi compact (eight genotypes), compact (HC 136). Sorghum genotypes having semi-loose to lose panicle shape give wide scope for selection to meet farmer's preferences especially in fodder production and area characterized with high rainfall. Such variations in panicle shape have being reported by Doggett (1988). Sangwan et al. (2005) studied identification of 12 sorghum genotypes on the basis of panicle compactness and shape of panicle. Elangovan et al. (2006) characterized 179 accessions of sorghum on the basis of earhead compactness, earhead shape, glume colour and earhead length. Reddy et al. (2009) characterized 29 sorghum genotypes on the basis of panicle length. Glume length, glume colour and grain colour of sorghum appeared to be more closely associated with grain mold resistance than other traits (Reddy et al, 2006). However, none of these traits was strongly associated with resistance. Genotypes could be divided into five groups viz., very short (three genotypes), short (six genotypes), medium (six genotypes), long (four genotypes) and very long (COFS 29) on the basis of glume length. Ringo et al., 2014) reported among selected 69 accessions some physio-morphological traits, such as taller plant height, loose to semicompact panicles, dark grain color and larger glumes coverage have been shown to be associated with grain mold resistance. However, brown seeded sorghums are often associated with relatively high tannin content and are less preferred by birds (Doggett, 1988). The genotypes having loose panicle and brown colour may be good for the fodder to preserve limited seeds produce. Genotypes were characterized into four groups $v i z$., white (three genotypes), yellow white (eight genotypes), yellow orange (SSG 5 (22) and SGL 87) and grayed orange (seven genotypes) on the basis of caryopsis colour. Chandgi-Ram et al. (1998) classified 30 sorghum genotypes on the basis of seed coat colour (white, brown and reddish). Nagaraja et al. (2000) characterized 23 sorghum genotypes on the basis of seed colour and seed shape in profile view into two categories while size of mark of germ into three categories. Selvaraju and Sivasubramaniam (2000) classified 19 sorghum varieties on the basis of seeds colour. Thangavel et al. (2005) classified 12 sorghum cultivars on the basis of seed colour, seed size, seed shape, size of mark of germ, texture of endosperm, colour of vitreous albumen and seed luster. Elangovan (2006) characterized 179 sorghum accessions on the basis of seed size and seed colour. Reddy et al. (2009) classified 29 sorghum genotypes on the basis of 1000-grain weight and reported wide range of variation in these genotypes. Elangovan and Babu, (2015) studied the genetic diversity among 99 sorghum landraces on the basis of 22 agro-morphological traits and found large genetic variation for days to flowering, leaf length, leaf orientation, days to maturity, plant height and grain luster.

To characterize the cultivars, descriptors are used to evaluate accessions in germplasm with the aim of expressing their attributes in a precise and uniform manner (Franco and Hidalgo 2003). Evaluation descriptors are used to determine the agronomic value of the accessions. A descriptor may be useful for both characterization and evaluation with the aim of reaching decisions about the accessions to be included in collections

Principal component analysis: Principal component analysis identifies few key traits contributing to the largest variation and could be a reliable method in predicting the important traits influencing clustering of different cultivars (Akatwijuka et al., 2016). Sharma (1998) reported that it reflects the importance of largest contributor to the total variation at each axis of differentiation. It was further reported by Fenty (2004) that PCA reduces a large set of variables to come up with smaller sets of components that summarise the correlations. Principal component analysis based on 16 characters gave 16 factors explained 100 per cent variation. The eigen values greater than one were considered to be significant (Hair et al., 1998). The first three principal components (PC) showed eigen values more than one and they together explained 77.69 per cent cumulative variability (Table 2 ). The maximum variation explained by first principal component ( 45.83 per cent) followed by second 19.15 per cent and third 12.71 per cent. To select the relevant characters in various principal factors, the correlation values above $(0.5)$ were considered as a relevant character for that principal factor. The first principal factor showed high loading for characters length of flag leaf, stem diameter, stigma length, plant height, leaf length, leaf width, neck of panicle visible above the sheath, panicle length, panicle length of branches, dry fodder yield, green fodder yield and thousand grain weight. Second factor score high loading for length of flag leaf, width of flag leaf anther length, leaf width, TSS content and $50 \%$ flowering. Third factor showed high loading for length of the flag leaf, Plant height and green fodder yield. Based on the various factors scores factor I and factor II provided maximum variability 64.99 per cent (Fig. 2). It explains that all the selected genotypes were distributed in all the coordinates. This indicated that selected genotypes had high magnitude of variability therefore; selection among these genotypes for further crop improvement could be beneficial. 


\section{Conclusion}

Characterization of sorghum genotypes used in present investigation based on 33 agro-morphological traits provided by Protection of Plant Variety and Farmer's Right Act (PPV and FRA) for Distinctiveness Uniformity and Stability (DUS) testing in sorghum indicated that studied genotypes had variation for these traits. Highest genetic variability is likely to be created by making crosses between selected genotypes from different groups and the genotypes having different characters for the development of new distinct variety. While, principal component analysis identified length of flag leaf, stem diameter, plant height and leaf length as key component traits associated with grain yield, could be use as key diagnostic traits for high fodder yield.

\section{REFERENCES}

Akatwijuka, R., Rubaihayo, P. R. and Odong, T. L. (2016). Genetic diversity among sorghum landraces of southwestern highlands of Uganda. African Crop Sci. J., 24 (2) $179-190$

Ali, M. A., Shahid, N., Amjad, A., Waseem, S. and Khawar, J. (2009). Genetic diversity and assessment of drought tolerant sorghum landraces based on morphphysiological traits at different growth stages. Plant Omics., 2(5) 214-227

Anonymous. (2001). Protection of Plant Varieties and Farmers Rights Act. (No. 53 of 2001). Deptt. of Agriculture and Co-operation. Ministry of Agriculture, Govt. of India, Krishi Bhavan, New Delhi.

Anonymous. (2004). National Guidelines for the Conduct of tests for Distinctness, Homogeneity and Stability of sorghum (Sorghum bicolor L.). ITG/03 sorghum, 28/10/03.1-16 (http://agricoop.nic.in/SeedTestguide/)

Anonymous. (2007). General Guidelines to the examination of DUS and the development of harmonized descriptors of plant varieties. Plant Var. J., 1:192-201

Ayana A. and Bekele E. (2000). Geographical patterns of morphological variation in sorghum [Sorghum bicolor (L.) Moench] germplasm from Ethiopia and Eritrea: Quantitative characters. Euphytica, 115: 91-104

Chandgi, R., Punia, R. C., Grewal, R. P. S. and Lodhi, G. P. (1998). Characterization of sorghum cultivars for tannic acid. Forage Res., 24(2): 125-126

Doggett, H. (1988). "Sorghum" Second edition. New York, USA: John Wiley and Sons. 512

Durrishahwar., Muhammad, N., Hidayat, R., Ihteramullah, Irfan, A. S., Farhan, A., Syed, M. A. S. and Nasir, M. (2012). Characterization of sorghum germplasm for various morphological and fodder yield parameters. Afr. J. Biotechnol., 11(56). 11952-11959

Earp, C. F., McDonough, C. M., Awika, J. and Rooney, L. W. (2004). "Testa development in the caryopsis of Sorghum bicolor (L.) Moench". J. Cereal Sci., 39:303-311

Elangovan, M., Prabhakar and Reddy, D. C. S. (2007). Characterization and evaluation of sorghum [Sorghum bicolor (L.) Moench] germplasm from Karnataka, India. Karnat. J. Agril. Sci., 20(4): 840-842

Elangovan, M. and Babu, P. K. (2015). Genetic variability and diversity of sorghum landraces collected from uttar pradesh, India. Indian J. Plant Genet. Resour., 28 (2):213-221

Fenty, J. (2004). Analysing distances. The Strata Journal, 4: $1-26$

Franco, T. L. and Hidalgo, R. (2003). Análisis estadístico de datos de caracterización morfológica de recursos fitogenéticos. Franco, T. L. \& Hidalgo, R. (eds.). Boletín Técnico Núm. 8 Instituto Internacional de Recursos Fitogenéticos (IPGRI), Cali, Colombia. 89

Hair, J. F. J., Anderson, R. E., Tatham, R. C. and Black, W. C. (1998). Multivariate data analysis. Upper Saddle River, NJ: Prentice-Hall.

Joshi, D. C., Shrotria, P. K., Singh, R. and Chawla, H. S. (2009). Morphological characterization of forage sorghum [Sorghum bicolor (L.) Moench] varieties for DUS testing. Ind. J. Genet. Pl. Breed., 69(4): 383-393

Joshi, M. A., Sarao, N. K., Sharma, R. C., Singh, P. and Bharaj, T. S. (2007). Varietal characterization of rice (Oryza sativa L.) based on morphological descriptors. Seed Res., 35: 188-193

Kannababu, N., Rakshit, S., Audilakshmi, S., Tonapi, V. A., Patil, J. V., Dhandapani, A., Reddy, D. C. S., Venugopal, K., Swarnalatha, M., Balakrishna Raghunath, G. K. and Subhakar, V. (2013). Genetic variability among Indian rainy season sorghum cultivars revealed by morpho-agronomic traits. Indian J. Genet., 73(1): 110-115

Madhusudhana, R. and Patil, J. (2013) A major QTL for plant height is linked with bloom locus in sorghum (Sorghum bicolor L. Moench). Euphytica., 191(2) 259268

Nabi, C. G., Muhammad, R. and Ghulam, A. (2006). Comparison of some advanced lines of Sorghum bicolor L. Monech for green fodder/ dry matter yields and morpho -economic parameters. J. Agril. Res. Lahore., 44(3): 191-196

Nagaraja, G. S., Varier, A., Singh, U. and Sharma, S. P. (2000). Characterization of inbreds and hybrids of sorghum \{Sorghum bicolor (L.) Moench\} by seed and seedling morphology and electrophoresis of seed proteins and isoenzymes. Pl. Var. Seeds., 13(1): 17-29

Raghuvanshi, S., Swamy, D., Mahadevakumar, S. and Singh, O. P. (2014). DUS discriptor of seventeen forage cultivars of sorghum [Sorghum bicolour (L.) Moench]. G.J.B.B. 3 (1): 100-108

Rakshit, S., Gomashe, S. S., Ganapathy, K. N. Elangovan, M., Ratnavathi, C. V., Seetharama, N. and Patil, J. V. (2012). Morphological and molecular diversity reveal wide variability among sorghum Maldandi landraces from India. J. Plant Biochem. Biotechnol., 21(2):145156

Reddy, B. V. S., Sharma, H. C., Thakur, R. P. and Ramesh, S. (2006). Special issue: Characterization of ICRISATbred Sorghum hybrid parents (set I). Int. Sorghum and Millets Newsletter, 47: 138

Reddy, D. C. S., Audilakshmi, S. and Seetharama, N. (2009). Genetic variability and divergence for DUS testing traits in sorghum (Sorghum bicolor). Ind. J. Agril. Sci., 79(4): 286-290

Reddy, R. N., Mohan, S. M., Madhusudhana, R., Umakanth, A. V., Satish, K. and Srinivas, G. (2008). Inheritance of morphological characters in sorghum. J. SAT Agril Res., 6: $1-3$

Ringo J.H., Mneney E. E., Onkware A.O., Owuoche J. 
Nabin Bhusal et al. / J. Appl. \& Nat. Sci. 9 (2): 912 - 919 (2017)

O.,Were B.A., Too E.J and Gudu S.O. (2014). Diversity of Sorghum (Sorghum bicolor L. Moench) Germplasm from Tanzania. J. Biol., Agricul Healthcare, 4 (24):3644

Sangwan, V. P., Chauhan, P. and Ram, C. (2005). Varietal identification of forage sorghum through morphological characters. Seed Res., 33(1): 117-118

Selvaraju, P. and Sivasubramaniam, K. (2000). Identification keys for sorghum varieties. Madras Agril. J., 87: 10-12

Sharma J.R. (1998). Statistical and biometrical techniques in plant breeding. New Age International (P) Limited Publishers, New Delhi, India. 432

Singh, S., Yadav, Y. P., Yadav, H. P., Vart, D. and Yadav, N. (2016). Morphological characterization of pearl millet hybrids [Pennisetum glaucum (L.) R. Br.] and their parents. Afr. J. Agric. Res., 11(5) 371-378

Thangavel, P., Bhatati, A., Natarajan, N. and Evera, T. (2005). Varietal grouping in sorghum by seed and seedling morphology and response to chemical testing. Karnat. J. Agril. Sci., 18(3): 664-672 